This PDF is a selection from an out-of-print volume from the National Bureau of Economic Research

Volume Title: Capital Formation and Economic Growth

Volume Author/Editor: Universities-National Bureau Committee for

Economic Research

Volume Publisher: Princeton University Press

Volume ISBN: 0-87014-197-X

Volume URL: http://www.nber.org/books/univ55-2

Publication Date: 1955

Chapter Title: Some General Reflections on Capital Formation and Economic Growth

Chapter Author: W. W. Rostow

Chapter URL: http://www.nber.org/chapters/c1314

Chapter pages in book: (p. 633 - 666) 


\title{
SOME GENERAL REFLECTIONS ON \\ CAPITAL FORMATION AND \\ ECONOMIC GROWTH
}

\author{
W. W. ROSTOW
}

MASSACHUSETTS INSTTTUTE OF TECHNOLOGY

\section{The Theme: Organized Disaggregation}

THE relation between capital formation and economic growth is a large part of the total problem of economic growth. Taking the rate of change of output to be a function of the rate of change in the size and quality of the working force and of the capital stock, this conference is analyzing the total growth problem, leaving the working force aside. And even then, in Levy's paper and elsewhere, the relation of capital formation to the size of the population-and even to the size and quality of the working force (Grossman)-has come into the discussion. We have taken on, then, a considerable and ramified set of issues.

Further, these issues are distinctly revolutionary. There appears to be complete unanimity-reflected in the substance of the papers as well as in the program of the conference-that the relation of capital formation to growth cannot be treated by the conventional tools of short-run economics. We appear to agree that, by definition, we are dealing with problems of rates of change over time rather than with short-period equilibrium; and that continuing changes in capacity, technique, and taste-normally, treated exogenously in modern economic theory, or in once-over change exercises-must somehow be introduced endogenously. More than that, we all appear to believe that an understanding of the relation between capital formation and economic growth demands that somehow, at some stage of the analysis, we bring to bear on the relevant economic variables social, political, and cultural forces which affect their net movement.

Because we agree about the range of the relevant variables, we come at this problem from many directions-in academic terms, from many different disciplines. The contributions here range from Lowe's austere theory through a spectrum of generalized but limited insights, based on empirical situations and data, back to that developing branch of social theory represented by Levy's contribution. At the present, early stage of concerted thought on growth, our con- 


\section{ROSTOW}

tributions necessarily must be partial. All the papers presented at the conference discuss one or another of the sub-determinants of the relation between capital formation and economic growth, rather than the relation itself, in its full complexity and grandeur.

We are, then, trying to make diverse bodies of data and diverse social science techniques effectively converge. On this view of our common problem, the present group of papers represent a major stride forward. There is an emergent area of common understanding-sometimes implicit, often explicit-as to how the various pieces of the puzzle fit together. There is more here than mere courteous acknowledgment that each has a right to his private line of approach. Not only is there agreement that we each have hold of a piece of the elephant; a consensus on the elephant's shape is also beginning to emerge. It is evident that we have been reading each other's articles and books. Before this conference I was inclined to the view that little actual work of synthesis had been done, beyond laudable programmatic statements. The noneconomic variables had not been satisfactorily related to the economics of the growth process. I think we can agree that this conference has made important progress toward this kind of synthesis. Although none of the studies presented for this conference pretend to meet the workmanlike vision of orderly growth analysis that Lowe holds up as a goal, a number of them go an important distance toward linking coherently the disparate variables that determine the relation of capital formation to economic growth.

There is, for example, Aubrey's systematic consideration of the manner in which the conventional profit maximization analysis of capital formation must be modified to fit the context of industrial enterprise in underdeveloped countries. This exercise goes well beyond empirical description. Hoselitz's reflections on British and French entrepreneurship since 1700 are explicitly linked to the relative scale of capital formation and over-all growth rates in the two countries; and Cochran seeks to make American entrepreneurial history illuminate Kuznets' American growth statistics. These papers are not merely summaries of odd institutional evidence. Similarly, Maclaurin's reflections on innovation pose questions of the first order of importance concerning the productivity of different kinds of investment and innovations. There are many other indications throughout these papers that the concerted study of a commonly understood problem is replacing methodological exhortation.

Under these circumstances the evident function of a commentator is to heighten a little our awareness of the links among the 
various approaches to growth analysis and to open up for general discussion the question of useful next steps. I shall simplify my task by elaborating a single arbitrary theme: the importance of organized disaggregation in growth analysis. This theme is relevant whether we are primarily concerned with making formal theoretical models of the growth process (Lowe); organizing rigorous statistical measures of historical patterns (Kuznets); examining functionally such sub-determinants of growth as the flows of loanable funds (Goldsmith) or the flows of science, invention, and innovation (Usher; Maclaurin, Cochran, and Hoselitz); defining current growth problems in particular settings (Aubrey, Grossman, and Holzman); or examining systematically the noneconomic motives and institutions which help determine the economic outcome (Levy). In all these tasks we must try increasingly to link the aggregate variables to organized knowledge of the components and sectors of which they are composed.

\section{Disaggregation and Growth Models}

It follows from this central theme that I have found the argument of Lowe generally sympathetic and suggestive. Although couched in the language of growth, the theoretical exercises of Harrod, Domar, Hicks, and Goodwin (and others) have not been concerned with the variables determining differences in the rate and structure of growth. Their primary purpose has been to demonstrate that the growth process is likely to proceed in unstable cycles of unemployment. By introducing a degree of disaggregation and by setting in motion some of the variables usually frozen in growth models, Lowe has linked income analysis to the problems of changing economic structure. He opens for formal examination the relations between over-all growth and the changing levels of sectorial capacity within the economy; and he makes clear the significance of the timing and sequence of structural change for cyclical and other disturbances.

The principal exercises on which Lowe concentrates are a onceover change in labor supply, the relation between changes in the consumption function and the structure of the economy, and the problem of factor displacement in technical change. These are all important cases. They permit Lowe to bring within the scope of rigorous formal treatment those problems in economic growth which are generally dealt with $a d h o c$, if at all. 


\section{ROSTOW}

At the end of his paper Lowe speculates on two major issues which belong high on the agenda for further analysis: first, the question of the capital-output ratio; ${ }^{1}$ second, the manner in which formal theoretical analysis can be related systematically to psychological, sociological, political, legal, and other variables which shape the growth process in real life.

I am convinced that we require far more extensive empirical analysis of the relation between changes in the capital stock and its total consequences for the level of output than we now have available. ${ }^{2}$ An improved understanding of the past and of relative growth rates among contemporary industrialized societies hinges on a clarification of the determinants of the productivity of different kinds of investment at different stages in the growth sequence. Our ability to prescribe appropriate patterns of investment for underdeveloped areas will also depend on the refinement of such knowledge.

We will have to go behind such global estimates of the capitaloutput ratio as those used by Lowe in his discussion of Singer's estimates (pages 632-633). The capital-output ratio as currently used is, after all, a kind of index number. Its level (and especially the interpretation of changes in it, or of differences in its level as among different areas) can only be understood in the light of an understanding of its components. Those who are now attempting to plan the pattern of investment outlays in underdeveloped countries make more or less explicit assumptions not merely about the total capital-output ratio but also about the short- and long-period effects on the level of output of investment in particular sectors; and they take into account not only sectoral differences but the cost of noncapital inputs as well. I would suggest that there is a weaker case for using over-all capital-output ratios than there ever was for focusing attention on over-all price or production indexes.

The lines of thought suggested in Lowe's paper which link savings-consumption balances to the structural problems of growth deserve to be pursued. But without losing touch with the aggregates which make up his (or other possible) growth equations, we might

1 The imperfections and ambiguities of the capital-output ratio as a general measure of capital productivity are being examined by others and will not be discussed in the present paper.

2 The author developed this theme at length in his unpublished paper presented before the 1953 conference of the International Economic Association at Santa Marguerita, Italy, "Trends in the Allocation of Resources in Secular Growth." 
usefully disaggregate our analyses beyond the level of his theoretical structure.

Over any particular period, in any national or regional economy which is growing, the growth process is carried forward by a relatively few major sectors. These may incorporate new technical possibilities, like the early British textile factories; they may reflect fundamental political decisions of the society, like the post-1945 boom in the armament industries of the world; they may reflect a newly indulged taste, as real income rises, like American suburban housing. These leading sectors set in motion behind them a whole train of secondary effective demands as, for example, suburbanization elevates the demand for automobiles and new commercial construction. Historically these leading sectors create external economies which facilitated the development of new leading sectors as the momentum of the old ones decreased. Thus, for example, the textile engineering firms moved into locomotives; and a steel industry built on rails turned easily to machine tools. In the end, the structural categories suggested by old-fashioned capital theory or by the categories of modern income analysis will have to be pierced to the point where the structural characteristics of growth can be examined with an intimacy and particularity Lowe does not attempt.

\section{Disaggregation and Statistical Analyses of Growth}

My observations on Kuznets' statistical essay relate closely to those I have made on Lowe's theoretical paper. Kuznets' work has produced an orderly body of data on the relation of capital formation to national product. In particular, he makes possible a quantitative assessment of the historical role of international capital movements in modern economic development.

Those who contribute statistical clarity to the murky field of economic growth put us especially in their debt. They have a right as well as a need to work within narrow analytic boundaries. The particular limitation that Kuznets accepts at the present stage is to postpone the measurement of the relation of capital formation to the rate of growth (as opposed to the relation between capital formation and the level of national income). I have no doubt that he has on hand, or ready at hand, systematic information on this central quantitative relationship. In fact, in his equally valuable statistical study, Goldsmith gives us (page 115) a table of growth rates which might be directly linked to Kuznets' figures on the proportion of national income invested at various stages in the growth process of Western nations. A portion of Kuznets' subject 
is, of course, narrower and more sharply focused than the over-all relation between capital formation and growth rates. He is concerned to measure roughly the quantitative importance of international capital flows, and to speculate on the meaning of the proportions that emerge.

When, as will surely happen, other analysts exploit this statistical breakthrough, they will have to proceed in terms not merely of the over-all scale (or proportion) of capital flows but of the particular directions in which they were used by the capital-importing nation. The story of international capital investment is tied up with particular stages in the growth of particular economies, and even with the situation in particular sectors. The capital exports from Britain in the 1830's, for example, can be understood substantially in terms of the world cotton market and the extension of cotton lands in the American South which proceeded in response to current and prospective cotton prices. At later stages in Anglo-American history, substantial British flows are intimately associated with wheat and railroads. In the late 1880's the major flows from London result from the emergence of the Argentine into some kind of political stability, which permitted it to bid for resources to finance basic port, railroad, and other facilities. To understand and to interpret fully the aggregate data Kuznets has supplied, we will have to study the components and examine the recognizable process which led to the ebb and flow of international funds.

I would suggest that Kuznets' generalization that "the volume of international capital exports was restricted primarily because the supply of savings available was limited" (page 43) may be modified when the evidence has been examined in the light of his calculations. Although the United States of the 1840's, for example, had immense if not unlimited long-run capital-absorptive capacity, it also had just passed through a land and public works boom in which the British investor lost a substantial part of his shirt. Americans could appear in the City of London in 1840 only at some personal risk; and the British at this stage turned their flows of investment inward to the development of their own railways. The limitation on international capital flows resulted from a changing balance between the attractiveness and the believed degree of risk in various rapidly developing parts of the world, and the attractiveness of home investment. Moreover, the expected (private) rate of return over cost could be high in domestic sectors where demand pressed against capacity, even when no dramatic technological in- 
novations were being introduced or rich new resources were being developed. The determinants of maximum short-run private profitability are not identical with the determinants of a maximum rate of growth.

In the end, of course, the limitation was, as Kuznets says, one of capital supply; for there were usually, in the nineteenth century, claimants on the international capital markets who were turned away. But international capital flows were the result of a somewhat more complex and shifting balance of market incentives and restraints than Kuznets' conclusion might indicate.

Speculating, for a moment, on what would happen if Kuznets' calculations were combined with data (for comparable periods) of the kind presented in Goldsmith's growth rate table, I suspect that we would find significant differences between the proportion of national income invested and the rate of growth, even among advanced countries, as well as differences within countries at different stages in their economic history. Kuznets' pioneering study (1930) on secular movements in production has demonstrated the universality of deceleration in particular sectors of the economy. There seems little doubt that among the forces which determine deceleration in particular industries is a kind of diminishing returns to particular forms of innovation. The capital-output ratio in the British cotton industry in 1790 was almost certainly quite different from that in 1840,1890 , or 1930 . The relative long-term stability of the overall capital-output ratio in certain advanced countries may well emerge as the result of the balancing out of differing rates among different industries at the same period of time, some young, others old. It will only be when we have quantitative knowledge of the capital-output ratio in different sectors of an economy, at different historical stages, that we will be able to understand differing overall levels, or even relative long-term stability in the over-all level.

Turning now to the other contribution of solid statistical substance (that of Goldsmith) I should like to make one comment in passing, strictly as an economic historian. My field has been bedeviled by a tendency to lapse into institutional description leading virtually nowhere from the economist's point of view. There is hardly a textbook in economic history which does not have its chapters or section devoted to the evolution of financial institutions. Occasionally thrown into these sections are brief and inadequate stories of

\footnotetext{
'See, for example, Brinley Thomas's discussion "Migration and the Rhythm of Economic Growth," The Manchester School, September 1951.
} 
financial crises, odd price data, and random reflections on the business cycle. So far as I know, Goldsmith's is the first effort to treat quantitatively the accumulated mass of data on the historical pattern of financial institutions in various countries, and the first effort to link such institutional analysis with the problem of capital supply and economic growth. Aside from its contribution to growth analysis, Goldsmith's paper is an important essay in economic history.

Like those of Kuznets and any others who deal with growth in orderly quantitative terms, Goldsmith's conclusions are limited by the nature and character of his data and the limited distance that he can go quantitatively in coping with the growth process as a whole. Nevertheless, his fundamentally agnostic interim conclusion (pages 158-160) conforms closely to the instinctive answer of an economic historian: namely, that men have made their economic purposes effective in an enormous variety of ways, and one would not expect a simple correspondence between particular kinds of institutions for mobilizing savings and the rate of growth. Modern economic history suggests a certain suspicion of firm correlations between particular institutional patterns (political, cultural, and social, as well as economic) and rates of growth.

One further comment on Goldsmith's paper. I am reasonably doubtful that, even after we have pursued the analysis of growth for several further decades, we will emerge with what a modern economic theorist would regard as a theory of economic growth. There are too many variables to be disciplined into forms where the number of equations are equal to the number of unknowns; and, even more important, the kinds of variables we would all wish to see introduced from the side of politics, social structure, and culture do not lend themselves to a Newtonian kind of theory, elaborated from clear, minimum arbitrary hypotheses. However, the technique of comparative morphology, of which Goldsmith's paper is a distinguished example, and for which there are important precedents in certain of the natural sciences, may prove highly appropriate to our problem.

\section{Invention, Innovation, and Entrepreneurship}

I turn now to four related papers presented to the conference by Usher, Maclaurin, Cochran, and Hoselitz. As Lowe says (page 622), "The theory of technical change is still a stepchild of economic analysis." In one part of our minds and in the ritualistic listing of the determinants of the level of investment and of the rate of growth, 
the state of technology has always had its formal place in economics. Moreover, Schumpeter and others have produced important and stimulating generalized observations on the process which lies between fundamental science and the productivity of investment inputs. What is lacking is a systematic view of invention, innovation, and the diffusion of innovation which might be effectively woven into a total analysis of the scale and productivity of capital investment.

If the Keynesian curve of marginal efficiency of capital has any operative meaning, it has always contained implicit assumptions about these variables. The level of effective demand for investment, in terms of expected rates of return over cost, has always depended not merely on the state of technology in some generalized sense but on the extent to which entrepreneurs were prepared to apply known innovations. ${ }^{4}$ Behind the level of capital demand, even in the short-run Keynesian sense, lie processes analyzed by Usher and Maclaurin and the qualities of entrepreneurship treated by Cochran and Hoselitz.

Usher's paper presents, in heightened form, the thesis with which his name has long been associated: namely, that invention is to be regarded as a continuous flow, representing the product of the more or less purposeful investment of a society in that peculiar creative sector, applied science. Against the background of evidence that Usher has amassed over the years, it is no longer tenable to treat invention and technical innovation as an exogenous force striking from time to time against the productive system through the medium of some Hegelian hero. Despite its peculiarities, invention is a normal part of the investment process, directed, like other forms of investment, toward believed areas of high rate of return over cost. Although Usher himself does not discuss this form of investment-the investment of resources in the generation of productive technical possibilities-in terms of a general theory of capital formation, it is time for economists to weave this variable into their analyses in a quite formal way. This demands that they include, among the sectors of the economy, that sector representing the current capacity to produce new technical improvements, and that they examine the order of magnitude of the investment input and its productivity in different societies at different periods.

\footnotetext{
${ }^{4}$ For an effort to link growth analysis to the Keynesian analysis of the determination of the level of investment see the present author's The Process of Economic Growth, Norton, 1952, pp. 65-69.
} 
Maclaurin's further observations on this theme indicate that to treat innovation in any kind of strict relation to capital formation, we must engage, again, in an important degree of disaggregation. Maclaurin has built up, from his examination of the innovation process in particular industries, persuasive evidence both for the changing productivity of innovation at various stages of an industry's history and for differences in the productivity of innovation as among sectors of the economy. His evidence reinforces the view that the capital-output ratio must be examined in terms of sectors of an economy. Maclaurin dramatizes the argument by exploring the prospects for investment productivity in advanced countries, where an increasing proportion of total output, and especially of new investment, goes into service and other nonmanufacturing industries. Here the natural sciences may not help the growth process as much as in periods when the heavy and engineering industries lead the way. Maclaurin's general argument comes to rest on prospects for the housing industry, which, apparently throughout the world, has resisted innovation with remarkable tenacity. He suggests that the maintenance of high investment productivity in advanced countries may depend on the generation and acceptance of housing innovations, to which the social scientist as well as the engineer will have to contribute.

Taken together, Usher's and Maclaurin's arguments add up to a strong case for including the scale and productivity of the flow of innovations as an important determinant of the capital-output ratio, and for alertness to the possibility of variations in that ratio arising from the historical stage of the innovation process in particular industries and sectors of the economy.

The arguments of Cochran and Hoselitz take us a step further. They are concerned to indicate, in the context of three countries (the United States, Britain, and France) the conditions under which men have been willing to undertake the risks of capital formation. While it is convenient and important in many analyses to distinguish the kind of risk-taking which goes into the lending of money from that associated with its borrowing or with the willingness to initiate or diffuse innovations, these various determinants of the scale and productivity of investment outlays tend to merge under certain institutional circumstances. The papers by Cochran and Hoselitz relate to both sides of the market for loanable funds. The early stages of British and American capitalism saw these separable elements in capital formation focused in the same institutions or 
even in the same persons. This identity remains partially with us in the current role of retained earnings in corporate finance, as well as in the role of governments as both entrepreneur and supplier of loanable funds on a substantial scale.

It is an important virtue of Cochran's essay that this issue and other analytical problems of general interest come clearly through his effort to take stock of the present position of American entrepreneurial study. His paper is heartening for those who have watched the development of the sprawling field of entrepreneurial research. It seemed for a time that we would be confronted by an endless series of histories of firms drawn up in implicit analytical terms derived simply from the firms' own records, without any link to the main body of thought and research on capital formation and economic growth. Although entrepreneurial study received an enormous impetus from the theoretical insights of Schumpeter, its first phase took the form of the amassing of empirical data, with little attention to its generalization or to its relationship with other bodies of thought. These individual studies varied, of course, in their general interest and quality; but they were characterized by a failure to relate the role of the entrepreneur to the other factors determining the firm's capital formation. The firm's history was often inadequately linked to the region of which it was a part and to more general aspects of the nation's economic history, as reflected in quantitative and other evidence of growth and fluctuations.

It is clear that Cochran is seeking to make this body of historical data illuminate the statistics, such as they are, and help explain changes in rates of capital formation in the United States. The links that are made by Cochran (for example, page 341 and especially pages 363-364) are certainly not as fine as the statisticians would desire or as Cochran would like to make. Nevertheless, it is evident that we have turned a corner in the field of entrepreneurial history. Cochran's paper is an indication that this field has begun to justify itself as a central part of the study of capital formation at its most generalized level.

Much the same kind of intellectual progress is represented in Hoselitz's paper on the comparative economic performances of Britain and France as they relate to the character and quality of entrepreneurship since 1700. Again we find a purposeful effort to link the conclusions on entrepreneurship to the over-all rates and patterns of growth. Although the number of entrepreneurial studies available on France is less than on the United States, the influence 


\section{ROSTOW}

of the unique social, political, and cultural structure of France as it operated through its entrepreneurs on the growth process has attracted some of the ablest men working in economic history. Hoselitz's extremely interesting effort at synthesis has excellent foundations.

These two essays in entrepreneurship illustrate once again the central theme of this commentary. When we deal with entrepreneurs, we are dealing with men who made decisions within individual firms and allocated the resources of individual firms. Our evidence is, by definition, micro- rather than macroevidence. We are in a Marshallian world of partial equilibrium when we examine the records of a firm, even a highly monopolistic firm. We are examining the supply of loanable funds, demand expectations, and the risks of innovation in the precise but limited settings of particular capital formation decisions. Our generalizations must be built up, therefore, from knowledge of firms to sectors of the economy; and, ultimately, as Cochran and Hoselitz have tried to do, these intermediate generalizations must be linked with over-all evidence on the rates and patterns of national growth. There is, however, an enormous jump from the microdata of the historian to the over-all, long-period growth rates to which Cochran and Hoselitz relate their entrepreneurial findings. As a result, their evidence can at the moment be brought to bear only in the form of broad generalizations and insights concerning the forces determining high or low, accelerating or decelerating, rates of growth. If, however, they had available systematic data on the growth rates of particular sectors of the economy, their evidence on entrepreneurship in particular industries at particular periods could be much more fully used. Qualities of entrepreneurship have always varied widely among the various sectors of an economy, and the data available to the expert on entrepreneurial history could illuminate the stories of sectors much more precisely than they can aggregate national statistics.

Moreover, in order to explore the meaning of aggregate growth statistics, we must, as noted earlier, examine them in the light of the differing growth rates in different sectors of the economy. Since entrepreneurial qualities are not uniform as among the sectors, we must bring our knowledge of entrepreneurial history to focus at the sectorial level. This will not preclude coming back again to the larger issues which Cochran and Hoselitz approach directly. It will mean that they will be able to approach these larger issues hav- 
ing moved up within a more systematic structure of analysis and a more systematic structure of statistical evidence than is now available to them.

\section{The Partial Equilibrium Analysis of Investment}

Although Aubrey's paper belongs, in subject matter, with the growing literature on problems of growth in underdeveloped areas, intellectually it stands with the essays of Cochran and Hoselitz. Like them, Aubrey has organized a vast amount of empirical data at an intermediate level of abstraction, thus rendering our knowledge of the facts more accessible and, especially, more susceptible of manipulation. Whereas Cochran and Hoselitz seek to make their data illuminate the relations between entrepreneurial quality and over-all rates of growth in three major countries, Aubrey's contribution is of a more general, theoretical nature. He systematically explains, in terms of a partial equilibrium analytic structure focused on the determinants of individual investment decisions, the differerences between the profit maximization model which governs our thought about investment in the Western world and the shape of the investment problem in underdeveloped areas. He demonstrates forcibly the manner in which the context of underdeveloped areas demands a relaxation or change in many of the implicit and explicit assumptions carried over from knowledge of the capital formation process in Western capitalist societies.

Within its narrow limits Aubrey's paper presents an orderly analysis of noneconomic variables. The social, political, cultural, and technical determinants of economic growth are carefully and precisely linked to the strictly economic variables which govern individual investment decisions. In the end we emerge with a heightened understanding of the clash, from the point of view of the individual investor, between profit maximization and security, and of the cross purposes which may develop between the interests of the individual investor and society as a whole.

Nevertheless, a key problem for growth analysis remains. How can Aubrey's evidence and analysis be translated into terms which would bear on the aggregate categories of such theoretical structures as Lowe's or which would illuminate aggregate data on underdeveloped areas of the kind Kuznets has mobilized on more advanced countries? The answer lies, again, I believe, in building up the study of sectors. At the level of a particular industry we can link the wealth of partial equilibrium data available to the aggregates and 
seize on the full determinants of the scale and productivity of investment. The leap is too great for systematic analysis without the sectorial substructure; and we are likely to shift from one side of the moon to the other, as we now tend to do, assisted merely by intuitive speculation. ${ }^{5}$

\section{The Soviet Case}

The two papers available on the Soviet Union, like many of the others, help clarify factors which determine the relation between capital formation and economic growth, without directly assaulting that key relationship.

The student of growth within a single economy has important prima-facie advantages over the general theorist or the functional specialist in one or another variable affecting the growth rate. The examination of a given country makes it vastly easier to bring into focus the full range of forces, economic and noneconomic, at work in the growth process. The unity of the area and the society under examination directly facilitates the unification of various strands in the analysis. It is quite natural for Holzman, for example, to weave into his treatment of Soviet inflation (page 261) the peculiar Soviet organization of the firm, brilliantly depicted in the various studies of Berliner. Although Holzman is concerned with a relatively narrow and clear-cut issue of public finance, he moves easily between his statistical data and the ideological, institutional, and other forces which determined the outcome for the price level.

Similarly, the analyst of a single national economy finds it easy, if not unavoidable, to treat the aggregates determining capital formation and growth in terms of sectors. There is a quality of intimacy in Grossman's analysis of current trends in Soviet capital formation. His insights into the meaning and problems of the Fifth Five-Year Plan, and the aggregate growth rate it incorporates, come alive for the reason that he is, by definition, examining over-all objectives in terms of their principal sectorial components. Capitalintensity ceases to be a remote antiseptic variable in an equation (pages $182 \mathrm{ff}$.). It is tied in ways that are quantitative in conception -if not exactly measurable-to the position in Soviet agriculture,

${ }^{5}$ For pioneering examples of the kind of sectorial analysis I have in mind see Paul G. Clark, "The Telephone Industry: A Study in Private Investment," and Anne P. Grosse, "The Technological Structure of the Cotton Textile Industry," in W. W. Leontief and others, Studies in the Structure of the American Economy, Oxford, 1953. 
housing, and even education, as well as to other sectors of the economy about which we can amass useful, if partial, evidence.

It is not accidental that some of the most original current work on capital formation and economic growth has arisen from speculation on the comparative economic performances of the United States and the U.S.S.R. We may or may not, over the years, be able to organize exact statistical evidence on the productivity of different kinds of investment outlays. But we should certainly be able to develop propositions, quantitative in character, which permit us to compare the growth patterns in different economies, and to isolate the reasons for differences among them. In his essay on "Capital Formation and Allocation" this is precisely what Kaplan did; and he concludes: "Thus, if the data can be believed, and if the analysis has been correct, the greater rate of increase of industrial output in the USSR [than in the United States] has been due, basically, not to differences in the USSR-United States rates of investment, but rather to differences in the direction of investment." 6

It has been my experience as a historian that neither the business cycle nor trend periods (in prices, interest rates, etc.) could be understood as historical phenomena until changing sectorial patterns of investment in the past had been examined. I am reasonably confident that the same body of data will emerge as central to the historical understanding of long-term growth rates and their determinants.

\section{The Contribution of Sociology}

We come, finally, to Levy's study of "Some Social Obstacles to Capital Formation in Underdeveloped Areas." This is a remarkable paper in several respects. First, Levy has taken care to clarify the economic determinants of capital formation before bringing to bear on them the insights of social theory. He has entered into the economist's problem, in terms recognizable to the economist. Second, he has chosen to state his preliminary hypotheses mainly in terms of a comparative analysis of two societies, those of Japan and China. In combination these qualities make possible a more detailed linkage of economic theory and social theory than one usually finds in interdisciplinary efforts. There is no quick generalization here, associating particular social systems with the conditions for rapid growth.

${ }^{6}$ In Soviet Economic Growth, Abram Bergson, editor, Row, Peterson, 1953, p. 80 . 


\section{ROSTOW}

Levy has begun to examine the components of social systems in relation to components of the economic process.

My sympathy for his approach derives from the agnosticism of the historian. Men have worked hard and imaginatively in the past out of a variety of motives. Economic progress has been achieved by societies as different in structure, institutions, and prevailing value systems as Britain and Japan, the United States and the Soviet Union. Neither Marxist theory nor any other general theory of society now available satisfactorily accounts for the diversities in pattern which societies have exhibited in general, and in their economic performance.

In contrasting the response of Japan and that of China to the challenge of Western industrial and military strength, Levy has chosen good illustrative material. They differ from the West, and they differ from one another. He has demonstrated how diverse the relations can be between the elements in an old culture and the requirements of industrial capital formation. On the whole, the inherited structure of Japan, as of the mid-nineteenth century, lent itself more easily to economic growth than did that of China; but this net conclusion arises from a complicated set of circumstances, not susceptible of easy generalization. Moreover (as Levy suggests, page 478), the comparison is incomplete unless we embrace in our analysis unique historical circumstances-e.g. the chronic military pressure on China, which Japan was spared, including the disastrous effects of the Japanese invasion (from 1931) on the social and economic structure of the Nationalist China which began to emerge in the 1920 's.

\section{Comparative Morphology and a Non-Newtonian Theory of Growth}

If it is true that we are unlikely to find simple associations between types of social structures (or cultures) and the conditions for economic progress, what becomes of the prospects for a general theory of economic growth? It is, of course, possible that in the fullness of time we shall develop an accepted general theory of society of which economics is one facet. Given the nature of the growth problem, nothing less is implied by the concept of a theory of economic growth. For the foreseeable future, however, our aim might well be more modest: to array the patterns of growth known to us in terms which permit systematic comparison. After all, the number of societies which have passed through the transition to industrializa- 
tion is limited. It should not be beyond the capacity of the social sciences to array the quantitative information available on them, in roughly uniform categories; and to explore the reasons for similarity and difference of pattern, in the light of the full determinants of economic performance. From such a grand exercise in comparative morphology, higher-order generalizations will surely emerge, relating both to the strict economics of growth and to the general social determinants of economic performance.

I believe that some such intermediate goal is implicit in most of the papers presented to this conference. The method of comparison of national patterns is used explicitly by Kuznets, Goldsmith, Hoselitz, and Levy; on a functional basis, the morphologist's technique is used by Aubrey, Maclaurin, and Usher; and, as indicated earlier, the general significance of the Soviet economic performance is increasingly being examined by means of international comparison.

I have tried in this paper to suggest the importance of sectorial analysis in furthering our understanding of economic growth. I believe it important for the refinement of theory; in the collection and interpretation of statistics; and, especially, as a means of linking systematically bodies of partial empirical evidence to aggregative concepts and data. Finally, meaningful international comparisons of growth patterns and processes require the building up of this intermediate level of analysis. The degree and kind of disaggregation appropriate will vary, as indicated in this paper, with the nature of the problem chosen for analysis and the nature of the data available.

In concluding I would make a further proposal: we might well attempt to codify, in a rough way, the measure of our theoretical agreement. Theory is a way of looking at things. Whether or not our various particular contributions will be susceptible of aggregation and cross comparison depends in part on whether we look at the growth process in similar ways. More technically, the usefulness of national growth studies will depend in part on whether or not we use comparable statistical categories and introduce into our analyses similar bodies of noneconomic data.

I am aware of the attachment that grows up between a social scientist and his private vocabulary, and of the dangers that inhere in the encouragement of abstract discussion in murky fields. Nevertheless, there may be some use in it for us, seeking to understand a many-sided problem, trying to use, in our own work, the results 


\section{ROSTOW}

achieved by colleagues whose training, vocabulary, and data are often unfamiliar.

\section{O M M E N T}

William J. Fellner, Yale University

My interpretation of Lowe's position will be based exclusively on the paper which he has submitted to this conference. On the other hand, in my interpretation of Rostow's position, I will also take account of his previous work. It seems to me that the essential characteristic of Rostow's position is his primary concern with the beginnings of growth processes in specific sectors of the economy, and their propagation through interrelations among the many sectors of our complex systems.

Rostow's and Lowe's analyses may be said to relate to two different aspects of the same problem-the relationship between longrun and short-run growth requirements. Both Rostow and Lowe place great emphasis on the necessity of analyzing the structure of resource specialization in connection with growth conditions.

I believe that the connections as well as the differences between these two contributions can be made clear by first distinguishing two types of structural analysis from each other, a long-run variety and a short-run variety, and by subsequently pointing out that both authors warn us effectively against relying on the long-run type of analysis without taking cognizance of certain results that can be obtained only by engaging in so-called short-run theorizing. The characteristic of short-run theorizing in this sense is that it deals with specialized resources-with different kinds of equipment rather than with "capital," and with different sorts of workers rather than with "labor."

In the aggregative models of recent years a basic condition of economic growth has been developed in terms of the rate of growth of output, the marginal capital-output requirement, the ex ante average propensity to save, and the rate of output itself. The aggregative condition is that the product of the first two of these four magnitudes should equal the product of the last two. In a continuously growing economy, this condition would have to be continuously satisfied. In an economy which shows merely long-run growth trends, there must be a long-run tendency toward satisfying this condition; that is to say, the violations of this condition must not permanently stop the growth process. Such aggregative theo- 
rizing must be supplemented by structural investigation, because by merely looking at the aggregative condition we cannot arrive at meaningful propositions as to the circumstances under which it is likely to be satisfied. Let us now distinguish between a longrun and a short-run variety of structural analysis, and then turn to the connecting links.

The long-run type of structural analysis directs attention to proportions between various broad categories of factors of production, in the unspecialized sense. On this level of analysis the fact that stands out most is that, in industrial economies, the capital stock is growing more rapidly than the supply of factors cooperating with capital. It would be unrealistic to assume that the growth process could continue against a lasting and substantial pressure of diminishing returns to capital. Consequently, we need improvements (innovations) to offset such a tendency. Furthermore, these improvements must have the effect of raising the marginal productivity schedule of capital, not just that of any factor of production. If improvements fail to raise the marginal productivity schedule of capital sufficiently, the growth process will be interrupted, excess capacity will develop, output will contract, and labor will become unemployed. While the improvements must be primarily capitalproductivity-raising (or labor-saving), they must not treat the productivity schedule of labor too badly, because if they do so, there will have to be a continuous decrease in the share of labor or a continuous increase in chronic unemployment. It is difficult to tell what the limits of tolerance of the system were in early times to a decrease in the share of labor. Today these limits of tolerance would be small; and we have reason to believe that, in fact, there has been no long-run tendency in this direction for many decades. The limits of tolerance to increasing chronic unemployment are nil, nor has there been a tendency toward this condition, although for a while the depression of the 1930's made some economists very pessimistic about this.

To repeat: improvements must raise the productivity schedule of capital sufficiently to offset the tendency toward diminishing returns to capital; at the same time, their relatively labor-saving character must not be so great as to turn the long-run labor scarcity into chronic superabundance of labor. In the long run, the character of improvements must tend to adjust to relative factor scarcities. This is the main problem which we detect on the first level of structural analysis. 
On the second or short-run level of structural analysis, we take account of the existence of specialized resources. Here another growth requirement meets the eye. Changes in the demand structure must be gradual enough not to overtax the mobility of resources; or, alternatively expressed, the mobility of resources must be sufficient to permit the specialized resource structure to adjust to the changing structure of demand. In a continuously growing economy this condition would have to be continuously satisfied. In an economy which shows merely long-run growth trends, each successive violation of the condition must be eliminated within a reasonable period of time. No individual violation must permanently arrest the growth process. This is the problem to which our attention is called on the second level of disaggregation.

It seems to me that the contributions of both Rostow and Lowe have the merit of warning us against forgetting about one level of structural analysis while we are moving on the other level. While it is methodologically convenient to distinguish the long run from the short run, we must recognize that the two interact, and that therefore resource specialization-commonly conceived of as a shortrun phenomenon-requires attention even in the interpretation of long-run tendencies. In other words, both papers prove that interactions make it necessary to keep one eye on one level while we engage in detailed analysis on the other level. Let us see how Rostow and Lowe accomplish this.

Rostow shows very clearly the significance of two circumstances of which it is easy to lose sight when an oversimplified account is given of innovational requirements.

One of these circumstances has to do with the phenomena of total effective demand, external economies, and technical complementarisms. Improvements in one industry or in one sector usually give rise to growth in other sectors-in supplementary sectors, to use Rostow's terminology-quite aside from the likelihood of further innovations in these supplementary sectors. Even along given production functions, it becomes more profitable to produce iron and steel if a railroad network has been constructed, and to build railroads if there exists a ferrous metal industry of appreciable capacity. For somewhat different reasons, it is more profitable to build suburban houses if there exists an automobile industry, and more profitable to manufacture automobiles if much of the population is suburban. Rostow's analysis confirms the impression that these demand interactions, external economies, and technical complementarisms 
must have been quite significant. In the early German protectionist literature, tariff arguments were based on considerations of this sort. Recently, it has become more usual to base an argument for over-all planning on these same considerations. Such tariff arguments or planning arguments are logically not without justification -the difficulty here of course is that tariffs, on the one hand, and over-all planning, on the other, possess disadvantages of a different kind. Rostow's paper is not concerned with the policy aspects of the problem, nor will I dwell upon them. However, I would like to draw an inference which relates to the innovational requirements of the economic system. On what I called the first, or longrun, level of structural analysis, I concluded that in each period new improvements are needed to prevent a pressure of diminishing returns from developing. The interrelations with which Rostow is concerned should make us think that the periods in which further new improvements are needed are considerably longer than the periods for which conventional marginal efficiency schedules are drawn. When the investments which equate the marginal efficiency with the rate of interest have been completed, the growth of total effective demand, external economies, and technical complementarisms may very well raise the marginal efficiency schedule for the next short period, even if there are no further improvements; and it may take many years before the next innovations of great significance are needed to offset diminishing returns. Of course, it would be very unrealistic to think that the growth of supplementary sectors is unconnected with further innovations. But the point here is that, as a consequence of demand interactions, external economies, and technical complementarisms, further innovational activity will not have to carry the entire burden.

However, Rostow's approach also proves that for another reason the proper adjustment of innovational activity to relative resource scarcities may become difficult in some periods. It is not unreasonable to expect a tendency toward more labor-saving innovations when the increase in the labor supply is especially small in relation to that of the capital supply, and to expect a tendency toward less laborsaving innovations when the discrepancy between the two is smaller. It is not unreasonable to expect an adjustment of the character of innovations to relative resource scarcities. But Rostow makes it clear that innovational activity must adjust to something else too. At different levels of the national income, there occur relative demand shifts of different kinds, and innovational activity will be 


\section{ROSTOW}

directed to opening up sectors which at that stage have potential for relative growth. Consumers become interested in automobiles when they are reasonably well-fed and -clothed, and not in the reverse sequence. The requirement that innovational activity should adjust to income elasticities of demand may be in conflict with the requirement that it should adjust to relative resource scarcities. Or rather, the adjustment to relative resource requirements may have to occur under considerable strain if other adjustments are also needed. For example, if labor is a relatively scarce factor and demand shifts call for developing a strongly labor-using sector-a sector with small capital-intensity-the labor-saving character of innovations will have to become all the more pronounced. Innovations will have to raise the capital-productivity schedules to a correspondingly larger extent.

In summary, I would like to suggest that Rostow's approach leads to certain conclusions with respect to the innovational requirements of growth, conclusions which prove that we have to keep an eye on the existing resource specialization even when we engage in long-run analysis and are primarily concerned with relative scarcities in broad factor categories. Innovations are needed because factor supplies in the broad, unspecialized sense do not grow at equal rates. But demand interdependence and external economies in specific industries and technical complementarism, which connects specific sectors of the economy, have a marked influence on the timing of the required innovational activity; and shifts in demand between different specialized sectors have exerted an important influence on existing degrees of relative factor scarcity.

It seems to me that Lowe's paper relates mainly to problems which develop on what I called the second level of structural analysis or disaggregation, where our attention is directed to the mobility or immobility of specialized resources. Lowe draws a useful distinction between investment goods industries producing equipment for other investment goods industries, investment goods industries producing equipment for consumer goods industries, and consumer goods industries. To any given demand structure there must correspond a pattern of resource specialization which is compatible with the required level of activity in these sectors. Starting from here, we may further disaggregate to any extent that seems methodologically desirable, but the general character of the specialization requirements can be made sufficiently clear in Lowe's initial three-sector model. It is clear that in a growing economy, or 


\section{SOME GENERAL REFLECTIONS}

for that matter in any economy with changing demand structures, the pattern of specialization will never be in equilibrium with the demand structure. There will always be some amount of wrong specialization. Sufficiently small maladjustments may be overcome simply by changes in inventories or by some degree of excess capacity or overutilization, while major maladjustments will interrupt the growth process. Whether these interruptions will be short or long (or will possibly degenerate into a permanent stoppage) should be expected to depend on the outcome of a race between mobility and the rate of recurrence of such maladjustments.

From Lowe's paper we may conclude that the limited mobility of specialized resources may interfere with innovational activity and with the growth process in general, even if the innovational process does meet the so-called long-run requirements. In this connection I would like to refer to Lowe's illustration of difficulties which may arise if ex ante savings and ex ante investment change in the same proportion, but change substantially. In terms of long-run analysis, one might expect continued smooth growth. But the structure of production would have to be rearranged to such a substantial extent that the pattern of specialization would be out of gear with the requirements of the situation. The question is not whether we call disturbances of this sort "short-run." It is whether in the clock-time long run they prove to be episodic. We are here faced with a race between mobility and wrong specialization. This is not the same as the classical race between diminishing returns and improvement, but the two "races" become interrelated with each other.

These are effective warnings against overlooking resource specialization with the excuse that our interest is in the "long run." Perhaps both authors are somewhat inclined to go too far in rejecting the traditional type of long-run theorizing. I am convinced that there are significant problems that are discernible by analysis that deals with broad, unspecialized categories of factors of production. In my comments I have explained what, in my opinion, these problems are. I don't know whether either Rostow or Lowe means to suggest that nothing essential becomes visible in theoretical frameworks that deal with "capital" and "labor" in general. At any rate, I would not go along with that proposition. But I fully agree that a useful theory of economic growth must pay a great deal of attention to problems which cannot even be posed before we take account of the specialized character of resources. 
Moses Abramovitz, National Bureau of Economic Research and Stanford University

When I undertook the assignment of commenting on Rostow's paper, I did not realize that his contribution would consist so largely of a review and systematization of the other papers presented at this conference. A discussion of Rostow's paper would, therefore, impose on me an uncomfortable degree of detachment from the original material. Under the circumstances I feel impelled to join more directly in the discussion of theoretical approaches to the economics of growth.

(1) My point of departure is the well-known fact that studies of long-term changes or persistent international differences in the level of economic activity inevitably bring into prominence a number of factors which have been understandably neglected in studies of short-term changes. These are factors which differ markedly from country to country but change only slowly over time. In studies of short-term economic movements in single countries, such factors are well treated as constants. But they are of the greatest importance for an explanation of continuing differences in levels of activity and rates of growth.

Among these neglected factors are such human qualities as enterprise, industry, mobility, adaptability, and thrift; and such aspects of economic and social organization as the effectiveness of a country's financial and business organization and the legal and traditional sanctions protecting property, contract, and person. Economists have been impressed with the probable importance of variation in such factors as these for explaining international differences and secular change in income, and have concentrated attention upon them, tried to assess their significance, and tried to trace their roots. In doing so, they have explored very bravely, but no doubt very awkwardly, territory which is quite strange and difficult for them. Instead of following the familiar paths traced by private pecuniary interest, they have stumbled among problems in which the influence of pecuniary interest seems remote: family organization in relation to enterprise and efficiency; the social prestige attaching to industry and trade compared with other occupations or no occupation; nonpecuniary attachments to locality, product, or method of work; the degree of habituation to abstract financial instruments; and so on through a great variety of factors which influence the energy and effectiveness with which people, as individuals or 


\section{SOME GENERAL REFLECTIONS}

groups, pursue their material advantage. In short, in this area economists pay the other social sciences the solid compliment of trying to be practitioners of their disciplines. And I suspect that, in addition to making a sociological or psychological contribution here and there, we are also going to discover how difficult the problems of the other social sciences are compared with those of traditional economics.

All this effort by economists outside the bounds of ordinary economics is right and proper. Like many other students, I have urged its necessity in connection with studies of economic growth. ${ }^{1}$ But the fact that our eyes are now fully opened to the importance of extra-economic considerations should not cause us to close them to the contribution which traditional economic considerations can make. I suspect there is some danger of this. Moreover, there is evidence that others feel the presence of this danger too. For example, Aubrey in his paper writes: "A sense of past neglect seems to impel economists to give, at present, more weight to 'noneconomic' factors. This tendency, however laudable and indeed inevitable, threatens to lead to disregard of the economist's own field of investigation" (page 397).

However this may be, there is surely a wide range of insights into long-term changes and international differences in economic development to be derived from traditional economics. I should like, therefore, to present-or, better, simply to recall-some ten theoretical propositions, or hypotheses, derived from orthodox economic reasoning, which should help to interpret the secular trends and international differences observable in capital formation measures. Just as in the case of the noneconomic factors, their range of application and their relative importance are still unknown. But they are plausible; they are subject to verification; and they deserve close study by economists interested in economic growth.

(2) The first two hypotheses are quite commonplace derivatives from the theory of production.

1. Capital formation, as a proportion of net national product, varies directly with the ratio of the labor force to the capital stock.

2. Capital formation, as a proportion of net national product, varies directly with the ratio of natural (i.e. "nonhuman" natural) resources to the stock of capital.

1 For example, in "Economics of Growth," in A Survey of Contemporary Economics, Bernard F. Haley, editor, İwin; 1952, Vol. I, pp. 132-178. 
The reasoning behind these two propositions is that, as among countries (or times) otherwise similar, the marginal productivity of capital will tend to be relatively high where (or when) the quantity of other resources is large relative to the stock of capital. Where the marginal productivity of capital is relatively high, it may be assumed that the backlog of unexploited opportunities to use additional capital profitably is relatively large. And the rate at which unexploited opportunities are seized-that is, the level of capital formation-is presumably related to the size of the existing backlog of such opportunities.

Some qualifications on the significance of these hypotheses must be made immediately. They assume diminishing returns to the factors of production, a tendency which may be defeated for many years by the economies of scale in the early development of "empty" countries. As between advanced and backward countries, it is doubtful whether the difference in the opportunities for gain, which these propositions express, will emerge from the welter of opposing forces. On the other hand, the propositions are consistent with the available evidence indicating that capital formation ratios in advanced countries fall in the course of economic development, at least after the early decades of industrialization.

3. Capital formation, as a proportion of net national product, varies positively with the rate of population growth. This proposition is evidently related to the first, but whereas the first expressed the effect of the cumulative backlog of investment opportunities, this expresses the effect of current additions to the backlog created by population increase. It may be presumed that current additions are of little significance if the cumulative backlog of unexploited opportunities is very large. On this reasoning, the proposition may be expected to be of importance only in relatively well-developed countries.

There is already a certain amount of empirical support for the hypothesis, but it 'needs' further refinement. In particular, the effects which operate through the size of the population at large should be distinguished from those which operate through the number of families; and from those which operate through the size of the labor force. It would be interesting, too, to discover whether population growth stimulates investment enough to cause capital stock to grow as fast as the number of people, and whether the investment so stimulated is disproportionately concentrated upon residential housing and community facilities. 
4. Capital formation, as a proportion of net national product, varies positively with the relative size of a country's capital goods industry. Keynes' treatment of the marginal efficiency of capital expresses the rationale of this hypothesis. The reasoning is that the rate of profit depends not only on the expected absolute yield from given additions to our physical equipment but also on their cost. The cost of capital goods varies positively with the level of investment because the capital goods industry, including the labor attached to it, cannot quickly be expanded. Thus the size attained by the capital goods industry at any time acts to limit the level of investment for considerable periods.

The significance of the hypothesis is somewhat limited by the fact that, to some extent, capital goods are produced by the same industries that produce consumer goods. To some extent, then, the distinction between capital formation and consumption is merely a matter of intent. Automobiles are an example.

More important is the fact that in some situations productive capital requires no special industrial outfit or organization for its production. The leading illustration is perhaps the capital embodied in cleared farm land wrested from a wilderness. The facts that this was the prime form of capital required by this and other new countries in their early development, and that for this purpose each pioneer farmer constituted his own capital goods industry, presumably help explain the rapid growth of some originally empty countries.

In all strictness, the argument applies only to a closed economy. For individual countries, capital equipment can be purchased as well as produced. Foreign purchases are, however, limited by a country's borrowing capacity, by the capacity of its export industries, by the elasticity of foreign demand for its products, and by the home demand for imported consumer goods. If, therefore, homeproduced investment is limited by supply conditions in the domestic capital goods industries, imports of capital goods are limited by conditions controlling the balance and composition of international trade.

5. A rising supply of money tends to raise the level of capital formation, and a falling supply tends to reduce it. The problem envisaged here arises when there is a secularly rising demand for goods which is made possible, not by prior increases in production in the manner contemplated by Say's law, but rather by increases in money demand. If such a rise in the demand for goods persists 
over many years, we may neglect the possibility of excess capacity and infer that prices will be rising. In this process a number of factors operate to encourage capital formation either singly or in combination. The new money may appear as an addition to liquid assets in the hands of individuals or firms. In that event, spending will be stimulated, and part of it is likely to be for capital goods. Alternatively, the additional money demand may arise in government spending based on new money or in foreign demand. In either case, there will be a strain on existing productive capacity, and the resulting profits will stimulate investment. Finally, the new money may appear as a result of the purchase of securities and loans with newly created bank money, and the consequent ease of financing will cause investment to rise. In all these cases, a general rise of prices eventuates which raises the general level of profits since, for well-known reasons, the prices at which goods are sold are likely to rise more rapidly than the prices which represent costs, at least so long as the pace of inflation is accelerating. The generally high level of profits stimulates investment partly because of the glow it casts on the future, partly because it encourages new investors to seek a share in existing markets, and partly because realized profits constitute an easy source of self-financing and an encouragement to lenders. It is this impact of general commodity inflation on investment which Keynes stressed in the historical analyses in the second volume of the Treatise on Money.

The range of application of this hypothesis is, of course, in doubt. Hayek and indeed most of the neoclassical writers seem to deny its validity altogether. They stress the fact that increasing injections of money are required to maintain investment booms based on forced saving. This, they maintain, produces recurrent collapses in which capital formation is discouraged. And since many investments stimulated by rising prices prove unprofitable when prices finally cease rising, let alone when they begin dropping, at least a portion of the capital produced during the boom goes to waste. It has also been urged, particularly in connection with backward economies, that chronic inflation diverts entrepreneurial energies from real capital formation to speculative trading in land, securities, and commodities, to the prejudice of productive investment. Since a priori speculation and common knowledge are incapable of settling the relation between the trends of money supply, prices, and the level of investment, the question deserves close study. 
6. Private investment, as a proportion of national product, varies directly with public investment. The argument which leads to this hypothesis is that there exists in every country a considerable range of valuable uses for capital which private business finds it difficult or impossible to exploit, because either the projects are too risky or the returns too long deferred or the venture too large or the benefits too diffuse to form the basis for private sale and profit. Examples of such social capital are familiar, and it is obvious that, once installed, they give rise to numerous opportunities for profitable private investment.

Attempts to verify and measure the strength of the relation between public and private investment will presumably have to allow for a lag of uncertain and variable length. They will also have to take into account the fact that public investment need not be direct; it can be indirect as in the cases of subsidy, loan, or guarantee of credit. Moreover, they will have to recognize that public investment in spheres in which profitable private operation is possible competes with private investment and so may have a negative net effect.

7. The international distribution of economic activity, and therefore of investment, shifts over time as a result of the impact of developing technology upon the distribution of locational advantages. The relation between technological advance and economic growth is, on the noneconomic side, still a mysterious process, involving the psychology and sociology of scientific progress, a theory of the translation of new knowledge into economically productive technology, and an understanding of the diffusion of the novel product or process within and between countries. Usher and Maclaurin have contributed to this aspect of the problem in their papers submitted to this conference-to say nothing of earlier work by them and others.

On the economic side, corresponding to any given "state of the arts," to use the old-fashioned phrase, there is, certeris paribus, a certain distribution of production throughout the world which maximizes total output or minimizes the total cost of a given output. This ideal international distribution of production is determined by the distribution of geographically fixed resources (including existing capital equipment and population insofar as they are immobile) taken in conjunction with the techniques available for exploiting resources and for transporting the resulting products to places of further manufacture and eventual consumption. The 


\section{ROSTOW}

static theory of location asserts, either explicitly or implicitly, that there is a tendency for the actual distribution of economic activity to approximate the ideal geographical pattern.

As technology progresses, however, shifts occur in the advantages that localities possess for production. The resources of some regions, which were of little importance before, become very valuable, while regions previously highly favored may lose some of their advantages. In the process of adapting economic activity to the changing pull of locational advantage, investment is stimulated in the former regions and discouraged in the latter.

Some of the very broad results of these shifts during recent centuries are clear: for example, the opening of continental interiors, the shift of activity from centers of surplus food supply to places rich in sources of power and industrial raw materials, and the trend toward spatial concentration of productive activity. But neither the empirical study of the impact of changing technology on the geography of production nor the adaptation of static location theory to the problem of differential rates of growth is yet far advanced. Both, it seems to me, deserve heavy stress in the near future.

I now add two hypotheses concerned with savings as a determinant of capital formation.

8. Capital formation per capita tends to rise with income per capita.

9. Capital formation per capita tends to decline as the distribution of income approaches equality.

The basis for the eighth proposition is Marshall's dictum that savings per capita vary directly with the "excess of income over necessary expenses." 2 The ninth requires additional support from the plausible but far from obvious notion that, as between income classes, absolute differences in saving increase more rapidly than absolute differences in income.

The eighth proposition implies no commitment to the questionable view that the ratio of savings to national income tends to increase as per capita income rises. However, both the eighth and ninth propositions assume that capital formation varies directly with the propensity to save. It will be recognized that this assumption may not be justified if investment demand at various levels of income is insufficient to absorb the available savings. Such in-

${ }^{2}$ Principles of Economics, 8th ed., London, Macmillan, 1920, p. 229. 
vestment insufficiency may be due to causes independent of saving, but it may also be due to saving itself when the profit from increasing output through investment depends on how much of an increment of real income tends to be spent.

A final proposition completes this decalogue of orthodox hypotheses:

10. Capital formation, as a proportion of national product, tends to increase as the proportion of income going to profits rises. In classical economics this proposition was implicit in the view that profits were the almost exclusive source of savings and that saving might be treated as identical with capital formation. In more modern writing the theory is supported by a variety of arguments. Unless the profit ratio is high because competition is restricted, the incentive to invest is stronger the larger the volume of profits. Next, the level of business saving presumably varies with the volume of profits. And business saving, since it constitutes self-financing, bypasses all the obstacles involved in bringing together the supply of saving and the demand for additional money capital.

(3) The purpose of these comments is merely to recall the insights which orthodox economic theory affords into the problems of economic growth. Since I do not wish to exaggerate the probable usefulness of such hypotheses as guides to an understanding of experience, a few additional remarks seem essential.

I have presented these ten propositions as derived from orthodox economic thought for two reasons. In the first place, the validity of each depends upon the effective operation of the profit motive. This implies that the propositions are likely to prove of greatest use in interpreting the course of events in those areas of the world and in those periods in which money income is highly valued and in which commerce is firmly established as an approved way of life. Orthodox economic theory, by its nature, is likely to be most useful in connection with developed countries or with the foreign activities of their nationals. But even in primitive economies the drive for gain is not wholly absent, and until a more systematic effort is made no one can tell how far orthodox reasoning can take us.

Second, the propositions attribute differences in the profitability of investment to the range of variables to which the older economists paid most attention-that is, the quantity of human and nonhuman resources, tastes, technology, and monetary conditions and policy. The profits to be earned by investment are, however, also influenced by a wide variety of factors connected with 


\section{ROSTOW}

economic and financial organization and with governmental policy. These presumably will have to be invoked to explain differences in capital formation not only between advanced and backward economies, but also among the countries in each group and in each country over time.

The study of the implications of economic organization, of law, and of governmental policy is a familiar branch of economics, though not perhaps of the orthodox variety. We may take Aubrey's paper to be a good example of this type of work. The study of variations in economic growth due to differences in the strength of pecuniary drives and to the degree of rationality with which income is pursued, and the investigation of the origins of economic institutions-here are the true happy hunting grounds of economic sociology, as Levy's paper suggests.

Granted the importance of orthodox theory, therefore, we can also easily see that it will have its limits. But even within the area in which such theory will best apply, the process of exploiting its insights will not be easy. This is likely to prove true in part because of the considerable number of variables which even orthodox reasoning suggests are important, in part because of the scarcity of reliable data, and in part because of the statistical problems of identifying the significant variables in the face of rampant covariation. Finally, part of the difficulty arises because the model of the secular trend of capital formation which the various orthodox hypotheses combine to form is unlikely to be one in which each factor exercises an independent influence in accordance with a simple mechanical analogy. Interrelations can already be discerned on the basis of our present scant knowledge: The contribution of savings to capital formation may be either positive or negative according to the strength of the inducement to invest and the behavioral characteristics of the money markets. The rate of population growth affects the inducement to invest through its influence upon the size of the labor force; but it also affects the supply of savings through its influence upon the ratio of workers to dependents and through the fact that the various income classes reproduce at different rates. ${ }^{3}$ The rate of population growth itself is presumably a function of the growth of income and, therefore, of capital formation. All this suggests that the application of orthodox reasoning to growth problems will involve not merely strenuous empirical investigation, but the solution of a variety of sticky theo-

s See Kuznets' paper, esp. Appendix C. 


\section{SOME GENERAL REFLECTIONS}

retical riddles. It also suggests that the attempt, exemplified in this paper, to recognize a dichotomy between economic and extraeconomic considerations can at best represent only a stage of work. The two sets of causes are too closely interwoven for either to be kept impounded during the stretches of time relevant to the problems of economic growth. 
: 